\title{
AJIS EDITORIAL
}

AJIS publishes high quality contributions to theory and practice in the world-wide Information Systems (IS) discipline, with an emphasis on the Australasian context of the research. The journal welcomes submissions on research and conceptual development based in a very wide range of inquiry methods, ways of thinking and modes of expression.

IS is a complex and dynamic field of study and activity. Its scope as a field of research and practice is contentious. An agreed hard and fast disciplinary boundary does not exist, and it would probably be counter-productive if it did. I expect, and hope, that the debate about what topics, issues, theories or methods are core to the discipline will be never-ending.

However, for an editor these matters are not 'merely academic'. I, with the advice of editorial board members and colleagues, need to make judgements as to the relevance of submissions to AJIS. In the development of this edition judged three submissions to be outside the scope of AJIS and suggested alternative journals to the authors. In these cases the submissions did not go to review. With some trepidation I list below broad topic areas that are of interest to AJIS and hasten to add that they are, of course, not exclusive. I have declined four papers on recommendation of reviewers and more papers are in their second or third revision.

This edition features three 'themes'. The idea of a featured theme is to allow parts of the discipline to present some of the best of their current work. Theme editors selected and evaluated papers then wrote an introduction showing why the theme is important in IS and how the papers contribute to it. My compliments and thanks to the theme editors. I am keen to continue this idea as it is an opportunity to look at a facet of IS more coherently and in more depth than is possible in a single paper. Themes that have been suggested for the future include IS and Governance, IS Philosophy and Virtual Communities. Please contact me with suggestions and offers to edit a theme in your area of interest.

My thanks to the paper authors and to Jennifer Bradley for her work on copy editing this edition. Thanks also to the School of Information Sciences and Engineering, University of Canberra for its financial support.

Craig McDonald

Associate Professor of Information Systems

University of Canberra, ACT, AUSTRALIA

Email: craig.mcdonald@canberra.edu.au

\section{Broad Information Systems Topics}

The nature of data, information and knowledge and their role in understanding, representing and acting in our personal, social and physical worlds.

The systematic interaction of people, organisations and information technologies; architectures and the impact of unsystematic technology adoption.

The analysis, design, deployment and management of information systems and the impacts of information systems on individuals, organisations and society.

Content domains (e-business, health informatics, government informatics, e-learning, etc) and cultural contexts for IS.

Multi-disciplinary integration to address information and systems in complex situations. 